\title{
Autoria e internacionalização na escrita acadêmica: análise da principal organização profissional das Engenharias Elétrica e Eletrônica
}

\author{
Larissa Giacometti Paris ${ }^{1}$ \\ Programa de Pós-Graduação em Linguística Aplicada, Universidade Estadual de Campinas, Campinas, \\ São Paulo, Brasil \\ Rómina de Mello Laranjeira ${ }^{2}$ \\ Programa de Pós-Graduação em Letras, Universidade Presbiteriana Mackenzie, São Paulo, Brasil
}

Resumo: Este artigo identifica e analisa as concepções de escrita acadêmica do IEEE (Instituto de Engenheiros Eletricistas e Eletrônicos), uma organização de relevância internacional na área. Para tal, utiliza procedimentos investigativos de base documental, caracterizando-se como uma pesquisa qualitativo-interpretativa. A partir do quadro teórico-epistemológico dos Letramentos Acadêmicos, analisa documentos do Instituto referentes à escrita e publicação de artigos científicos, com foco na autoria e internacionalização da produção científica. Em relação ao primeiro elemento, observa-se que a definição de autoria, associada a questões de ética na publicação, evidencia relações implícitas de poder institucional, no âmbito da cultura da velocidade. Em segundo lugar, conclui-se que as orientações disponibilizadas pelo IEEE, no que concerne à escrita em inglês, evidenciam uma perspectiva centrada no domínio das habilidades técnicas, perpetuando desigualdades entre o centro anglo-americano e os falantes não nativos de Inglês, na conjuntura atual da internacionalização da ciência.

Palavras-chave: Letramentos Acadêmicos; Autoria; Internacionalização; Engenharia.

Title: Authorship and internationalization in academic writing: analysis of a leading professional organization in Electrical and Electronic Engineering

Abstract: This paper seeks to identify the academic writing conceptions of IEEE (Institute of Electrical and Electronics Engineers), an organization of international relevance in its field. To this end, it uses document-based investigation, characterizing itself as a qualitative and interpretative research. Based on the Academic Literacies theoretical and epistemological framework, this paper analyzes documents from the Institute concerning the writing and publication of scientific articles, focusing on authorship and the internationalization of scientific production. First, we observe that the definition of authorship is related to an ethical

\footnotetext{
${ }^{1}$ Mestra e doutoranda em Linguística Aplicada, bolsista CNPq, processo número: 141101/2017-2, Universidade Estadual de Campinas. Orcid: http://orcid.org0000-0002-1472-0581

E-mail: larissagparis@gmail.com

${ }^{2}$ Doutora em Ciências da Educação, especialidade em Literacia e Ensino do Português (Universidade do Minho/Portugal), pós-doutoranda em Letras (bolsista PNPD/CAPES, processo número: 88882.314881/2019-01, Universidade Presbiteriana Mackenzie. Orcid: https://orcid.org0000-00026854-101X

E-mail: romello.laranjeira@gmail.com
} 
dimension in publications, highlighting implicit institutional power relations within the culture of speed. Secondly, we conclude that IEEE's guidelines for writing in English emphasize a technical skills-centered perspective. This perpetuates inequalities between the Anglo-American center and non-native English speakers within the current trend of science internationalization.

Keywords: Academic Literacies; Authorship; Internationalization; Engineering.

\section{Introdução}

O campo da escrita no ensino superior é atualmente um terreno fértil de pesquisa em diversos países, tendo vindo a se desenvolver, nas últimas décadas, diferentes epistemologias teóricas e metodológicas que se debruçam sobre o tema, com seus objetos de estudo e recortes particulares. Assim se observa e compreende alguma oscilação no próprio conceito, ora escrita acadêmica, escrita científica, escrita científico-acadêmica, letramento(s) acadêmico(s). Neste artigo, de modo a contribuir para e aprofundar a discussão sobre a publicação de artigos científicos e internacionalização, consideramos pertinente um olhar debruçado sobre o IEEE, o mais importante instituto e sociedade profissional da área das Engenharias Elétrica e Eletrônica a nível mundial.

A partir do quadro teórico-epistemológico dos letramentos acadêmicos, oriundo dos Novos Estudos de Letramento (STREET, 1984), pretendemos identificar as concepções de escrita acadêmica do IEEE, com foco na autoria e internacionalização do conhecimento científico. Para tanto, analisamos (i) o website do Author Center e (ii) o template de 2017, segundo uma análise documental dos referidos documentos disponíveis online.

Em um primeiro momento, elaboramos uma breve história do IEEE, mostrando a relevância do instituto na área das Engenharias Elétrica e Eletrônica, no âmbito da pesquisa e publicação de artigos científicos. Em seguida, apresentamos o quadro teórico que sustenta a análise documental realizada e apresentada num terceiro momento. Por últimos, tecemos algumas considerações finais que rematam os argumentos elaborados ao longo da análise.

\section{Breve história do IEEE}

O Instituto de Engenheiros Eletricistas e Eletrônicos (doravante IEEE, lê-se "i-três-és") é a maior sociedade profissional técnica do mundo ${ }^{3}$ e foi criada para atender profissionais envolvidos em todos os aspectos dos campos da elétrica, eletrônica, computação e áreas afins

\footnotetext{
${ }^{3}$ Nessa seção, os dados e as informações referentes à história do IEEE foram retirados do website oficial do instituto. Disponível em: <https://www.ieee.org/about/ieee-history.html>. Acesso em: 07 dez. 2018.
} 
da ciência e da tecnologia. O IEEE conta com associados de diversas áreas do conhecimento, tais como cientistas da computação, desenvolvedores de software, profissionais de tecnologia da informação, físicos, médicos e muitos outros, além do núcleo original de engenheiros eletricistas e eletrônicos.

As raízes do IEEE remontam a 1884, ano em que um pequeno grupo de profissionais da área da elétrica se reuniu em Nova York, nos Estados Unidos, com o intuito de criar uma nova organização para apoiar profissionais em seu campo. É válido recordar que, ao final do século XIX, já havia uma importante indústria elétrica estabelecida, principalmente com o surgimento do telégrafo, na década de 1830. Essa nova organização recebeu o nome de Instituto Americano de Engenheiros Eletricistas (AIEE, sigla em inglês) e teve como primeiros associados profissionais que vieram a se tornar mundialmente reconhecidos, como Thomas Edison e Alexander Graham Bell. Com o passar dos anos, o AIEE tornou-se cada vez mais focado em energia elétrica e, através de reuniões técnicas, publicações e desenvolvimento de padrões, o AIEE liderou o crescimento da profissão de engenharia elétrica nos Estados Unidos.

Paralelamente à criação do AIEE, uma nova indústria começou a crescer, a partir do surgimento da telegrafia "sem fio" em 1895, que depois viria a se tornar o rádio. Com essa nova indústria, foi criada também uma nova sociedade em 1912, denominada Instituto de Engenheiros de Rádio ou IRE, sigla em inglês da associação. O IRE foi criado nos mesmos moldes do AIEE, mas dedicando-se aos profissionais que trabalhavam com o rádio, tais como engenheiros eletrônicos.

Ao longo do século XX, o IRE recebeu mais associados que o AIEE e se tornou o maior grupo de profissionais da área. Ao perceberem que havia interesses em comum em ambos os institutos, em 1 을 de janeiro de 1963, o AIEE e o IRE se fundiram para formar o Instituto de Engenheiros Eletricistas e Eletrônicos, ou IEEE. Em sua formação inicial, o IEEE possuía 150.000 membros, dos quais 140.000 residiam nos Estados Unidos.

Desde sua criação até aos dias de hoje, os campos de interesse do IEEE expandiram-se bem além da engenharia elétrica, eletrônica e da computação, em áreas como micro e nanotecnologia, ultrassom, bioengenharia, robótica, materiais eletrônicos e muitas outras. Além disso, o instituto, com o passar dos anos, passou a ser reconhecido internacionalmente pela comunidade acadêmica da área.

Os dados mais recentes divulgados pela associação, referentes ao ano de 2017, revelam que o IEEE conta com mais de 417.000 membros, em mais de 160 países, desde estudantes de graduação e pós-graduação, a profissionais da área e pesquisadores. Desses, mais da metade são membros de fora dos Estados Unidos. Além disso, possui mais de 4 milhões de documentos na Biblioteca Digital IEEE Xplore ${ }^{\circledR}$, com mais de 8 milhões de downloads por mês, sendo responsável pela publicação de aproximadamente 200 anais de eventos, periódicos e revistas, e patrocinando mais de 1.800 conferências em 98 países.

De acordo com a associação, isso corresponde a quase um terço da literatura técnica mundial em engenharia elétrica, ciência da computação e eletrônica, ainda levando em 
consideração que os periódicos do IEEE estão entre os mais citados nessas áreas. Todos esses dados, divulgados no website 4 oficinal do IEEE, demonstram a relevância do instituto para o campo da engenharia elétrica e eletrônica, tornando-se uma indústria poderosa no meio científico-acadêmico.

\section{Fundamentação teórica: Letramentos Acadêmicos}

De acordo com Street (2003), os Novos Estudos do Letramento representam uma nova maneira de conceitualizar a natureza do letramento, ao criticar a visão dicotômica entre fala e escrita, bem como a redução do letramento a um conjunto de competências e variáveis discretas de domínio (ou não) da linguagem. A aquisição de habilidades deixa de ser o único foco, ao mesmo tempo em que os pesquisadores consideraram o letramento como prática social (STREET, 1984). Nesta perspectiva, tal posição teórica e epistemológica leva a teoria do NLS (sigla, em inglês, para New Literacy Studies) a reconhecer a multiplicidade dos letramentos, que variam no tempo e no espaço (STREET, 2003) e, portanto, são entendidos como práticas situadas. Desse modo, e considerando o ambiente social de interação, analisamse práticas de letramentos que, de fato, se inserem em situações concretas do uso social da linguagem (FISCHER; COLAÇO, 2017), caracterizando-se, então, como práticas sociais.

Além disso, ao serem compreendidas como sociais, também é possível relacionar as práticas de letramentos às relações de poder específicas de uma comunidade. Segundo Fiad (2015), os NLS criticam a concepção de escrita da cultura ocidental que a considera como neutra e independente dos processos sociais, históricos e culturais. Nesta medida, privilegiamse os gêneros do discurso das classes dominantes, marginalizando os outros gêneros (FIAD, 2015). Fisher e Colaço (2017, p. 441) afirmam que as relações de poder enraizadas em práticas sociais constituem a natureza desigual dos letramentos, considerando que "se alguns letramentos são legitimados por instituições, outros, em consequência, são desvalorizados". As autoras ainda argumentam que determinados discursos da esfera acadêmica legitimam como se deve escrever e quem está autorizado a fazer isso.

Para os pesquisadores do NLS, as práticas de letramento possuem caráter situado, o que significa afirmar que têm significados específicos em diferentes instituições e grupos sociais. Segundo Fischer,

letramento representa maneiras sociais e culturais de se proceder através do uso de textos. Essa visão adiciona à compreensão de letramento as maneiras que os indivíduos, grupos, comunidades e sociedades colocam as práticas letradas em funcionamento (FISCHER, 2010, p. 218).

\footnotetext{
${ }^{4}$ Disponível em: https://www.ieee.org. Acesso em 17 mar. 2019.
} 
Ao considerar contextos sociais específicos, Fiad (2011) afirma que se torna possível assumir a existência de múltiplos letramentos, a depender das diferentes esferas e grupos sociais.

Nesta conjuntura, surgem os estudos sobre os letramentos acadêmicos, em que "assume-se que há usos específicos da escrita no contexto acadêmico, usos que diferem de outros contextos, inclusive de outros contextos de ensino" (FIAD, 2011, p. 362). A autora também reitera que algumas das práticas socioculturais de escrita ocorrem em situações tão particulares que os sujeitos necessitam estar inseridos nessas práticas para que consigam produzi-las (FIAD, 2013), sendo este também o caso dos letramentos acadêmicos. Essa expressão, portanto, refere-se "ao conjunto de práticas sociais que envolvem leitura e escrita nos contextos da universidade e com finalidade acadêmica" (FISCHER; COLAÇO, 2017, p. 439).

As pesquisas que se baseiam na perspectiva dos letramentos acadêmicos surgiram a partir dos estudos de Lea e Street (1998) que, ao pesquisarem sobre a produção escrita de estudantes no Ensino Superior, chegaram à conclusão de que há três modelos relacionados às práticas de letramentos no contexto acadêmico: habilidades de estudo, socialização acadêmica e letramentos acadêmicos. Vale ressaltar que os autores sublinham que tais abordagens não são mutuamente exclusivas, mas que características de uma foram englobadas nas outras. Também não devem ser entendidas de modo linear. Ao contrário, muitas vezes, os modelos coexistem nas diversas práticas acadêmicas e uma mesma prática pode possuir significados diferentes dependendo da perspectiva adotada (LEA; STREET, 1998).

O modelo de habilidades de estudo assume que a escrita é técnica e instrumental, sendo necessário aprender determinadas habilidades - que podem ser transferidas de um contexto para o outro - para tornar-se apto a escrever no contexto acadêmico (LEA; STREET, 1998). O foco desta perspectiva é o de "consertar" os problemas de escrita do estudante, ao colocar a ênfase nas competências que não tem e construindo, desta forma, uma visão deficitária do discente. Neste sentido, o letramento é concebido tanto como uma habilidade individual, quanto cognitiva (LEA; STREET, 2006), mas que desconsidera a trajetória anterior dos letramentos do aluno (FIAD, 2013).

Por sua vez, o modelo da socialização acadêmica parte do princípio de que o professor deve introduzir os alunos na "cultura acadêmica", em um processo de "aculturamento de estudantes em discursos e gêneros baseados nos temas e nas disciplinas" (LEA; STREET, 2006, p. 369). O intuito é que os discentes "assimilem os modos de falar, raciocinar, interpretar e usar as práticas de escrita valorizadas nas disciplinas e áreas temáticas da universidade" (FIAD, 2015, p. 28). De acordo com Lea e Street (1998), esta perspectiva pressupõe que haja uma "cultura acadêmica" relativamente homogênea, em que basta aprender as normas e as práticas para se ter acesso a toda a instituição, considerando ainda assim a escrita como sendo transparente (LEA; STREET, 1998).

Os modelos de habilidades de estudo e socialização acadêmica, todavia, 
desconsideram determinados aspectos ideológicos da esfera científico-acadêmica, conforme assegura Miranda:

\begin{abstract}
a apreensão da avaliação social específica para cada prática de escrita de que participa um universitário nem sempre ocorre de forma perceptível, uma vez que se pode compreender as regras da língua e as convenções sociais, porém, há possibilidades e restrições que não estão explícitas em convenções e dizem respeito a relações de poder, às condições de produção ou a questões institucionais que afetam, diretamente, os gêneros - e estilo dos gêneros acadêmicos - a serem produzidos pelos universitários, já que a esfera da universidade é uma esfera ideológica (MIRANDA, 2017, p. 86).
\end{abstract}

O modelo dos letramentos acadêmicos, distinto dos outros dois, "coloca em primeiro plano a natureza institucional daquilo que conta como conhecimento em qualquer contexto acadêmico específico" (LEA; STREET, 2006, p. 369).

Segundo Lea e Street (1998), ao invés de compreender a produção escrita como um conjunto de habilidades ou como fruto de uma socialização, assume que a escrita se relaciona a questões epistemológicas e identitárias. Pasquotte-Vieira (2015, p. 696) considera que o terceiro modelo "tem como perspectiva a necessidade de discussão e negociação para a integração dos sujeitos aos contextos situados de produção escrita, interlocuções e relações de poder". A ênfase nas relações de poder, na identidade e nos significados sociais que emergem das práticas corrobora o foco também nos conflitos ideológicos (LEA; STREET, 1998). Assim, este modelo é especialmente relevante para a escrita científico-acadêmica, na medida em que contempla a perspectiva dos sujeitos envolvidos e os contextos de produção dos gêneros acadêmicos (MIRANDA, 2017).

Conforme mencionado, analisamos as concepções de escrita acadêmica, presentes nos documentos do IEEE, segundo o quadro teórico-epistemológico dos letramentos acadêmicos.

\title{
Metodologia
}

Essa é uma pesquisa qualitativa-interpretativa com procedimentos investigativos de base documental. Para Lüdke e André (1986) a análise documental é uma técnica valiosa de abordagem de dados qualitativos, podendo revelar aspectos novos de um problema ou temática de pesquisa. As autoras ainda afirmam que a análise documental é válida, na medida em que os documentos são escritos em um determinado contexto e fornecem informações sobre uma situação de produção específica, tal como se afigura o nosso objeto neste artigo. Nesse tipo de investigação, os documentos caracterizam-se por não terem recebido nenhum tratamento científico até o momento da análise (SÁ-SILVA; ALMEIDA; GUINDANI, 2009), caso contrário, poderiam ser considerados objetos de uma pesquisa bibliográfica, e são utilizados 
como "fontes de informações, indicações e esclarecimentos que trazem seu conteúdo para elucidar determinadas questões e servir de prova para outras, de acordo com o interesse do pesquisador" (SÁ-SILVA; ALMEIDA; GUINDANI, 2009, p. 05).

É papel do pesquisador, então, fazer inferências e reconhecer indícios relacionados aos valores e aos aspectos ideológicos referentes às fontes ou aos autores do documento analisado (LÜDKE; ANDRÉ, 1986), situando-os em relação ao contexto sócio-histórico em que foram originalmente produzidos. O intuito da análise documental é criar novas maneiras de compreender os fenômenos e determinar novas tendências, a partir da sintetização e interpretação das informações presentes nos documentos (SÁ-SILVA; ALMEIDA; GUINDANI, 2009).

Lankshear e Leander (2005), no artigo Social science research in virtual realities, discutem sobre diferentes aspectos das pesquisas, cujos objetos são produzidos em realidades virtuais. Para os autores, a pesquisa baseada na análise de documentos online utiliza a internet como uma ferramenta para coleta de dados e/ou para análise e interpretação. Pesquisas documentais que analisam dados produzidos em ambientes virtuais, portanto, baseiam-se no florescimento constante de arquivos e de bancos de dados online (LANKSHEAR; LEANDER, 2005), característico de contextos virtuais em que não há a limitação imposta pelas buscas laboriosas de documentos impressos em locais físicos, por exemplo.

Ao fazermos um recorte dos documentos disponíveis, analisamos tanto textos publicados no website Author Center, quanto o template que é recomendado ao autor, quando a sua área de pesquisa não está contemplada nos modelos fornecidos. Tal template é considerado um modelo de artigo científico mais abrangente para as áreas de engenharia elétrica e eletrônica, ou seja, não foi produzido com o propósito de contemplar as subáreas dessas engenharias.

\section{Modelos de escrita e formatação dos artigos}

O Author Center ${ }^{5}$ é um website, criado pelo IEEE, que visa auxiliar o pesquisador em diversos aspectos relacionados à prática de escrita científico-acadêmica, sugerindo um processo por etapas a serem cumpridas para conseguir publicar: desde se "tornar" autor, criar um artigo, submeter até ao que acontece depois da publicação. Encontramos instruções e indicações sobre ética na pesquisa científica e direitos e responsabilidades do autor; textos sobre o modo de funcionamento da avaliação dos artigos, explicitando, por exemplo, a questão da revisão por pares; disponibilização de diferentes ferramentas, com a função de recomendar o melhor tipo de publicação (a partir do perfil do artigo); recursos que visam a revisão de gráficos produzidos e a validação do uso de referências bibliográficas; e, por fim,

\footnotetext{
${ }^{5}$ Centro do Autor (tradução nossa).
} 
vídeos tutoriais. Veja-se a página inicial do website:

Figura 1 - Página inicial do website IEEE Author Center

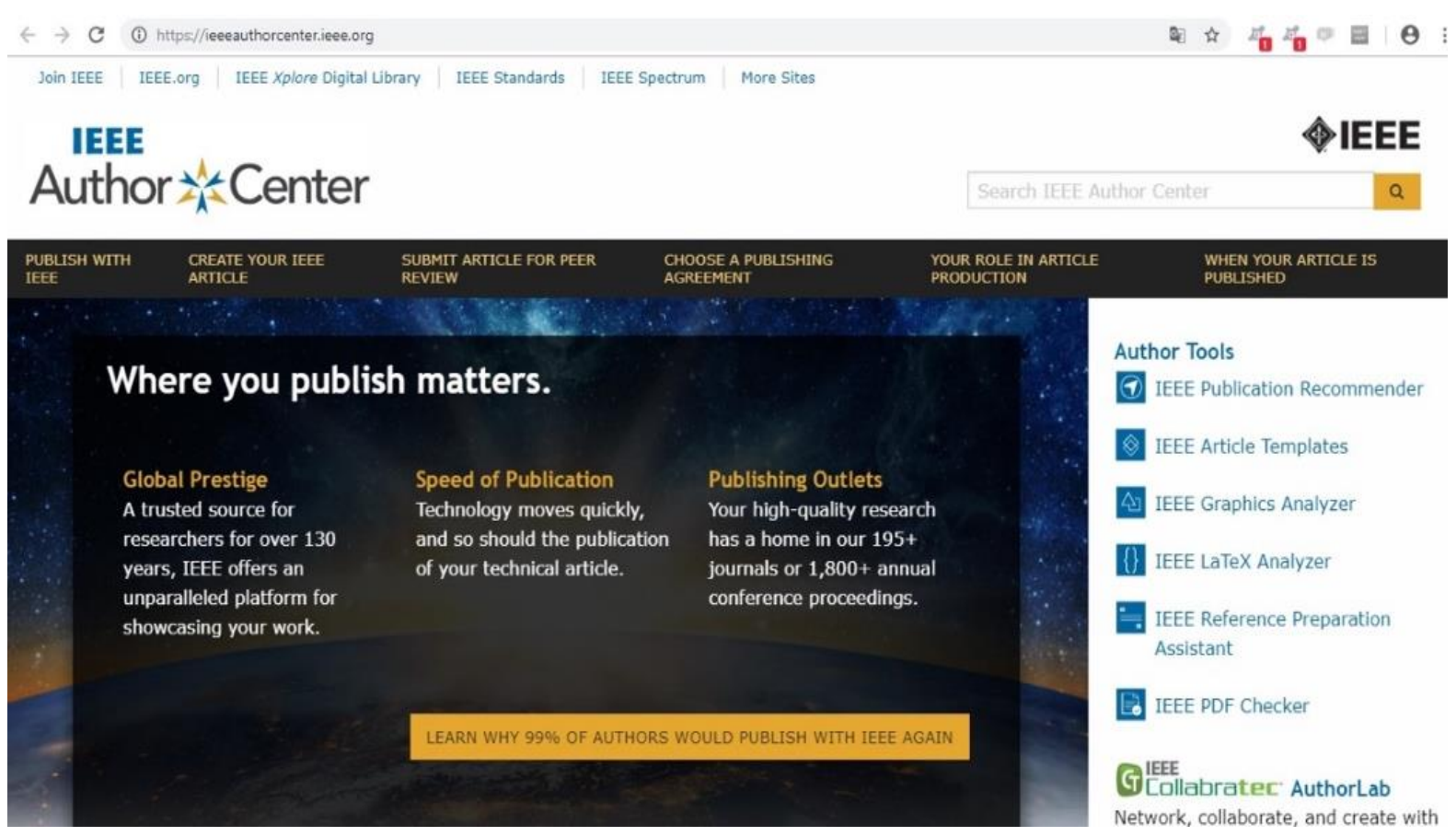

Fonte: IEEE Author Center. Disponível em: https://ieeeauthorcenter.ieee.org/. Acesso em 24 jan. 2019.

Uma das ferramentas para autores, denominada IEEE Article Templates $^{6}$, que visualizamos à direita da página, apresenta dezesseis templates para a escrita de artigos científicos, sendo que cada um equivale a um modelo de formatação de texto para periódicos de áreas específicas. Assim, há um template para artigos pertencentes à área de eletrônica industrial e outro para a área de eletrônica quântica, por exemplo, conforme é indicado na figura a seguir. O foco de análise, contudo, se dará apenas no template que não especifica uma área.

\footnotetext{
6 Modelos para artigo do IEEE (tradução nossa). Disponível em: https://journals.ieeeauthorcenter.ieee.org/create-your-ieee-article/authoring-tools-andtemplates/ieee-article-templates/. Acesso em 28 jan. 2019.
} 
Figura 2 - Templates de artigos científicos produzidos pelo IEEE

\author{
IEEE Article Templates \\ Easily format your article with an IEEE article template. \\ Article templates help you prepare a draft of your article for peer review. Templates help \\ with placement of specific elements such as the author list in addition to providing \\ guidance on stylistic elements such as abbreviations and acronyms. Select the appropriate \\ template from the list below; if you don't see your target publication listed, use the \\ Transactions templates. \\ - Templates for Transactions \\ - Templates for Computer Society Journals \\ - Template for IBM Journal of Research \& Development \\ - Templates for IEEE Access \\ - Templates for IEEE Journal of Electromagnetics, RF and Microwaves in Medicine and \\ Biology \\ - Templates for IEEE Journal of Quantum Electronics \\ - Templates for IEEE Journal of Translational Engineering in Health and Medicine \\ - Template for IEEE Journal on Exploratory Solid-State Computational Devices and Circuits \\ - Templates for IEEE Magnetics Letters \\ - Template for IEEE Photonics Journal \\ - Template for IEEE Sensors Letters \\ - Templates for IEEE Transactions on Antennas and Propagation \\ - Template for IEEE Transactions on Dielectrics and Electrical Insulation \\ - Templates for IEEE Transactions on Industrial Electronics \\ - Templates for IEEE Transactions on Magnetics \\ - Template for IEEE Transactions on Medical Imaging
}

Looking for conference templates? Visit the conference publishing website to access Word and LaTeX conference templates.

Fonte: IEEE Author Center. Disponível em: https://journals.ieeeauthorcenter.ieee.org/create-yourieee-article/authoring-tools-and-templates/ieee-article-templates/. Acesso em 24 jan. 2019.

De acordo com o website, os modelos devem ser utilizados para formatar o texto do autor, embora não apresentem apenas orientações relacionadas à formatação, como veremos adiante.

No Quadro 1, apresentamos a descrição dos documentos analisados neste artigo, a partir do ano de publicação, número de páginas, formato e propósito. Na última coluna, destacamos qual a finalidade de cada documento, de acordo com o contexto de produção. 
Quadro 1 - Caracterização dos documentos do IEEE sobre escrita científico-acadêmica

\begin{tabular}{|c|c|c|c|c|c|}
\hline $\begin{array}{c}\text { Tipo de } \\
\text { Documento }\end{array}$ & Título(s) & Ano & $\begin{array}{c}\text { № de } \\
\text { páginas }\end{array}$ & Formato & Objetivo \\
\hline $\begin{array}{l}\text { Textos } \\
\text { publicados } \\
\text { no Author } \\
\text { Center }\end{array}$ & $\begin{array}{l}\text { Become an } \\
\text { IEEE author; } \\
\text { Speed of } \\
\text { Publication; } \\
\text { IEEE Author } \\
\text { Tools; } \\
\text { Definition of } \\
\text { Authorship; } \\
\text { Publishing } \\
\text { Ethics, entre } \\
\text { outros. }\end{array}$ & $\begin{array}{l}2018 \\
\text { (frequentemente } \\
\text { atualizado no } \\
\text { website) }\end{array}$ & $\begin{array}{l}\text { Não se } \\
\text { aplica }\end{array}$ & $\begin{array}{l}\text { Publicação } \\
\text { em } \\
\text { website }\end{array}$ & $\begin{array}{l}\text { Oferecer ao autor } \\
\text { um local virtual em } \\
\text { que possa } \\
\text { encontrar } \\
\text { orientações, } \\
\text { ferramentas, } \\
\text { serviços e modelos } \\
\text { de documentos } \\
\text { referentes à escrita } \\
\text { científico- } \\
\text { acadêmica, às } \\
\text { políticas de } \\
\text { publicação do } \\
\text { instituto e aos } \\
\text { congressos e } \\
\text { periódicos } \\
\text { pertencentes ao } \\
\text { IEEE. }\end{array}$ \\
\hline $\begin{array}{l}\text { Template } \\
\text { de artigo } \\
\text { científico }\end{array}$ & $\begin{array}{l}\text { Transactions } \\
\text { template } \\
\text { and } \\
\text { instructions } \\
\text { on how to } \\
\text { create your } \\
\text { article }\end{array}$ & 2017 & 09 & $\begin{array}{l}\text { Word ou } \\
\text { LaTeX } \\
\text { (download } \\
\text { disponível) }\end{array}$ & $\begin{array}{l}\text { Fornecer } \\
\text { orientações ao } \\
\text { autor para a } \\
\text { preparação e } \\
\text { formatação de } \\
\text { artigo científico, } \\
\text { disponibilizar um } \\
\text { modelo } \\
\text { (“template”) para a } \\
\text { escrita de artigo } \\
\text { científico. }\end{array}$ \\
\hline
\end{tabular}

Fonte: As autoras 


\section{Requisitos autorais}

Partindo das questões em torno da internacionalização e publicação em inglês, por falantes nativos e não nativos, analisamos a concepção de autor e autoria, disponibilizada no Author Center, associada a questões de ética e cuja definição apresentamos na figura seguinte:

Figura 3 - Texto publicado na seção "Ética de publicação" do Author Center

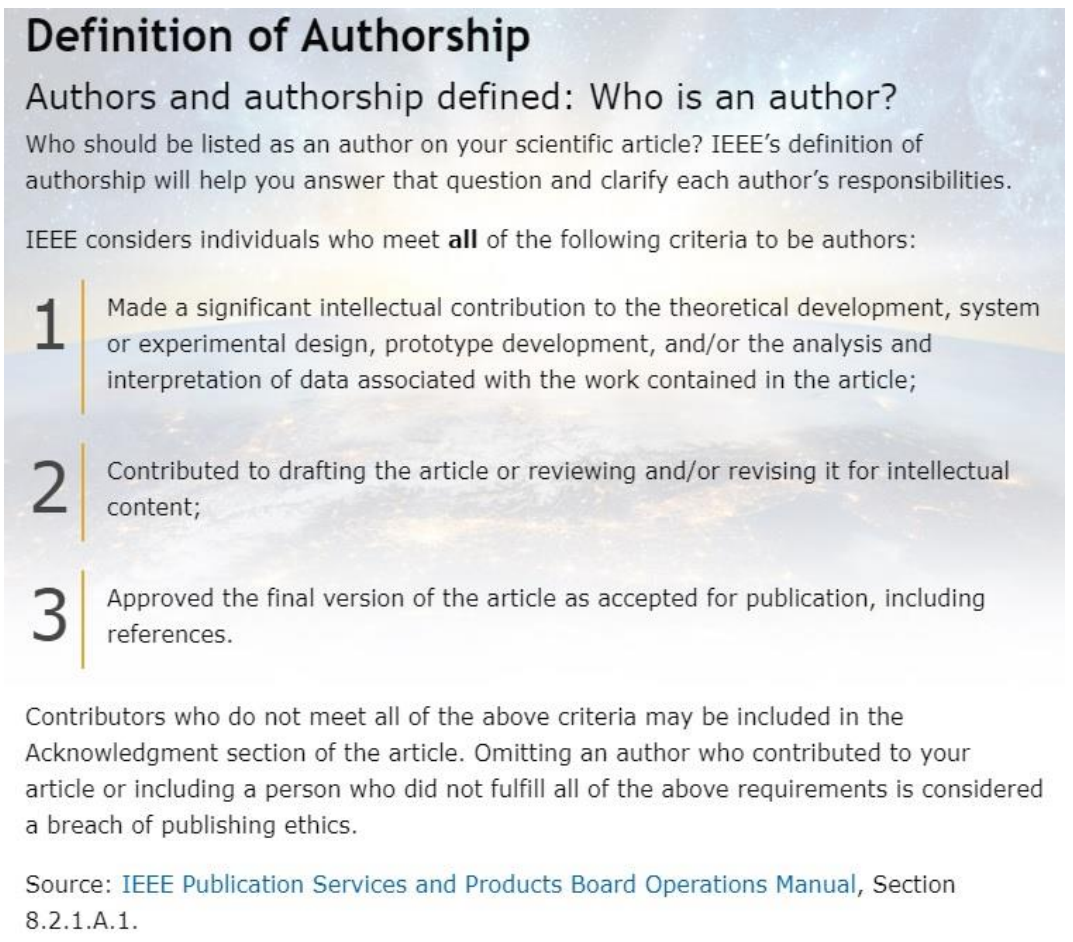

Fonte: IEEE Author Center. Disponível em: https://ieeeauthorcenter.ieee.org/publish-withieee/publishing-ethics/definition-of-authorship/. Acesso em: 26 nov. 2018. ${ }^{7}$

\section{${ }^{7}$ Definição de Autoria}

Autores e autoria definidos: Quem é autor?

Quem deve ser listado como autor em seu artigo científico? A definição de autoria do IEEE ajudará você a responder a essa pergunta e a esclarecer as responsabilidades de cada autor.

O IEEE considera indivíduos que atendem a todos os seguintes critérios para serem considerados autores:

1. Fez uma contribuição intelectual significativa para o desenvolvimento teórico, sistema ou desenho experimental, desenvolvimento de protótipo e/ou análise e interpretação dos dados associados ao trabalho contido no artigo;

2. Contribuiu para redigir o artigo ou corrigi-lo e/ou revisá-lo para conteúdo intelectual;

3. Aprovou a versão final do artigo como aceito para publicação, incluindo referências.

Os colaboradores que não atenderem a todos os critérios acima podem ser incluídos na seção de Agradecimentos do artigo. Omitir um autor que contribuiu para o seu artigo ou incluir uma pessoa que não cumpriu todos os requisitos acima é considerada uma violação da ética de publicação.

Fonte: Manual de Operações da Diretoria de Produtos e Serviços de Publicação do IEEE, Seção 8.2.1.A.1. (Tradução nossa) 
Um primeiro elemento de análise que queremos ressaltar é, de fato, a política de publicação que o IEEE determina ao explicitar todos os requisitos a cumprir simultaneamente para se ser considerado autor. Não basta uma contribuição teórica, experimental, analítica ou de resultados, é necessário também ter escrito, revisto e/ou corrigido o conteúdo intelectual do texto, e ainda, a concordância com a versão final do trabalho. Acreditamos haver positivamente uma tentativa de definir questões de ética autoral, mas, ao mesmo tempo, consideramos que estão em jogo "dimensões escondidas" e relações de poder institucional, de acordo com Street (2009). Devemos indagar o que significa fazer uma contribuição "significativa", e mais ainda, quem decide sobre essa importância. Além disso, se um dos três requisitos listados não for cumprido, o instituto considera tal ato uma falha ética. Mais uma vez, questionamos, de que forma o IEEE garante que os autores cumprem essa prática aqui indicada? Em segundo lugar, podemos, então, inferir que todos os artigos aceitos e publicados pelo IEEE cumprem essa política de publicação, definição de autor e autoria e regras éticas?

Um segundo elemento, decorrente do primeiro, é a possibilidade concreta de perceber, com este exemplo, como a escrita acadêmico-científica é uma prática social situada e constituída por relações discursivas e de poder entre pessoas, instituições e identidades sociais. De acordo com Fischer (2010), as formas de realizar as práticas de letramento - e destacamos aquelas da esfera científico-acadêmica - são modos culturais de utilização da linguagem. Nestas práticas, portanto, há relações de poder implícitas e sutis. Dessa maneira, verificamos que a prática de publicar em coautoria, diríamos, em numerosa coautoria, que é uma prática consolidada na área, como sabemos, está profundamente associada a relações de poder, de ética, de ideologia e institucionais. Também não devemos esquecer que o número de citações de um trabalho, e logo, de um autor, é altamente relevante para a consolidação profissional e institucional, pensando na avaliação da produção científica nos dias de hoje, quantitativamente extrapolada. Diríamos ainda que tornar-se autor, ou seja, pertencer a certo grupo, implica alcançar um elevado número de citações, desde que ressalvadas as questões de ordem ética e intelectual, talvez nem sempre asseguradas atualmente, em função das exigências que têm constituído as práticas de publicação. Esta questão nos leva ao ponto seguinte: a publicação em inglês.

\section{Internacionalização e publicação em inglês}

A relevância do IEEE também é evidente no contexto brasileiro. Em uma consulta à plataforma Sucupira ${ }^{8}$, constatamos que, dos 214 periódicos classificados como A1 pela CAPES

\footnotetext{
${ }^{8}$ Disponível em:

https://sucupira.capes.gov.br/sucupira/public/consultas/coleta/veiculoPublicacaoQualis/listaConsulta GeralPeriodicos.jsf. Acesso em 07 dez. 2018.
} 
para a área de conhecimento Engenharias IV (Engenharia Elétrica e Engenharia Biomédica), 85 pertencem ao IEEE, ou seja, 39,71\% dos periódicos $\mathrm{A} 1$ pertencem a um único instituto. Tal dado revela indícios, portanto, relacionados à esfera institucional da área. Considerando que quase $40 \%$ dessas revistas são organizadas pelo IEEE, podemos inferir que o instituto desempenha um forte papel ao fornecer parte das diretrizes, orientações e políticas de publicação dessa comunidade científica, ainda que provavelmente dialogue com discursos oficinais de agências de pesquisa norte-americanas, tal como acontece no Brasil entre os periódicos e os órgãos de fomento à pesquisa (FUZA, 2017), como a CAPES e o CNPq, por exemplo.

Além disso, para a área de conhecimento Engenharias IV, a mesma consulta mostrou que não há periódicos brasileiros qualificados como A1. Sendo assim, se um pesquisador brasileiro deseja publicar sua pesquisa, em periódicos classificados como A1 pela CAPES, deve, necessariamente, buscar uma revista internacional, o que obriga à escrita do artigo em língua inglesa. O cenário da internacionalização da pesquisa científica, ao menos na área das engenharias elétrica e eletrônica, já faz parte do contexto brasileiro.

Considerando esse contexto de produção, e partindo do pressuposto de que o pesquisador da área necessita escrever em língua inglesa, caso deseje publicar em periódicos A1, selecionamos dois excertos relacionados à escrita em inglês e disponibilizados no Author Center e no template de artigo científico (p. 2). Vejamos, a seguir, o excerto 1 publicado no Author Center, que corresponde ao 3o passo da seção Create the text of your article? .

\section{Excerto 1}

\section{Refining the Use of English in Your Article Communicate your work clearly.}

If English is not your native language, consider using an English language editing service before submitting your article for review. An expert editing service can help you communicate your work more effectively. The use of an editing service is paid for by the author and does not guarantee acceptance in an IEEE publication.

IEEE authors are eligible for discounts at the following language editing services:
Excerto 1 (tradução nossa)

Refinando o uso do inglês em seu artigo Comunique de forma clara.

Se o inglês não for sua língua nativa, considere usar um serviço de edição em inglês antes de enviar seu artigo para avaliação. Um serviço de edição especializado pode ajudá-lo a divulgar seu trabalho com mais eficiência. $\mathrm{O}$ uso de um serviço de edição é pago pelo autor e não garante a aceitação em uma publicação do IEEE.

Os autores do IEEE são elegíveis para descontos nos seguintes serviços de edição

\footnotetext{
${ }^{9}$ Crie o texto do seu artigo (tradução nossa).
} 
- American Journal Experts: $10 \%$ discount

- Enago: $30 \%$ discount de idiomas:

- American Journal Experts: desconto de $10 \%$

- Enago: desconto de $30 \%$

Inicialmente, salientamos a concepção de linguagem como ferramenta de comunicação (GERALDI, 1984), presente neste excerto. Diferentemente da noção de linguagem como interação, tal concepção idealiza a língua como um código em que basta ao emissor e ao receptor o domínio (ou não) das regras desse código para que a comunicação seja (ou não) efetivada. Nesse sentido, se o autor do artigo e seus leitores (respectivamente o emissor e os receptores, de acordo com essa concepção) dominarem bem o código da língua inglesa, a divulgação da pesquisa - ou seja, a transmissão da mensagem - se dará de maneira mais eficaz (Communicate your work clearly e communicate your work more effectively ${ }^{10}$ ).

Em contrapartida, caso o autor não seja um falante nativo da língua, justifica-se a oferta de um serviço de tradução ou de revisão para a língua inglesa, visando uma comunicação mais "clara" e "eficaz", segundo o IEEE. Entretanto, essa concepção desvincula a língua de seu aspecto cognitivo e social (MARCUSCHI, 2008) e, consequentemente, desconsidera o uso da língua em contextos sociais mais amplos $(\mathrm{KOCH}, 2000)$, resultando em uma ideia de linguagem supostamente transparente.

Além disso, a ênfase no domínio do código da língua inglesa dialoga com os princípios do modelo de habilidades de estudo descrito por Lea e Street (1998). Nessa perspectiva, a escrita é vista como técnica e instrumental, sendo necessário dominar determinadas habilidades da escrita acadêmica para tornar-se apto a escrever. Se a questão se resume ao domínio do código e das habilidades técnicas, um serviço de tradução para a língua inglesa resolveria todos os percalços enfrentados por autores não falantes de língua inglesa para a internacionalização da pesquisa científica?

Acreditamos, por isso, que as concepções de linguagem como instrumento de comunicação e de prática de escrita como um conjunto de habilidades técnicas, ambas presentes nesse excerto do Author Center, revelam indícios de que o IEEE, enquanto instituição, não assume a escrita a partir de sua esfera ideológica acadêmica (MIRANDA, 2017), ou seja, desconsidera as condições de produção, bem como as relações de poder existentes nesta esfera que constituem as práticas de letramentos acadêmicos.

No template de artigo científico, destacamos o excerto 2:

\footnotetext{
${ }^{10}$ Seja claro na comunicação e seja mais eficaz na comunicação (tradução nossa).
} 


\section{Excerto 2}

Remember to check spelling. If your native language is not English, please get a native English-speaking colleague to carefully proofread your paper.
Excerto 2 (tradução nossa)

Lembre-se de verificar a ortografia. Se a sua língua nativa não for o inglês, peça a um colega nativo falante de inglês para revisar cuidadosamente o seu trabalho.

O excerto 2 é um trecho presente na introdução do template do artigo científico na subseção denominada "outras recomendações". Tanto os profissionais que realizam os serviços de tradução recomendados, no excerto 1, quanto a figura do colega revisor, nesse último excerto, podem ser considerados mediadores de letramento (LILLIS; CURRY, 2010).

O termo foi cunhado por Lillis e Curry (2010) em um estudo realizado com cerca de cinquenta pesquisadores de doze instituições de diversos países. As autoras comprovam que a prática de escrita acadêmica não envolve apenas a figura do autor, mas também a de muitos outros sujeitos que de alguma forma causam impacto direto na trajetória da publicação de um artigo científico, tal como amigos, editores, pareceristas e tradutores.

Os mediadores de letramento que, de alguma forma, auxiliam na escrita em inglês são divididos em duas categorias por Lillis e Curry (2010): mediadores linguísticos e mediadores acadêmicos. Os primeiros são, geralmente, profissionais especialistas na língua inglesa, tal como tradutores, revisores e professores de inglês. Já a segunda categoria envolve pesquisadores que trabalham em universidades e institutos de pesquisa em contextos anglófonos e que, normalmente, pertencem à mesma área de conhecimento do autor do artigo.

O estudo revelou que os pesquisadores evitavam solicitar uma tradução de seus textos aos mediadores linguísticos devido a dois motivos: o alto custo do serviço e a falta de precisão na tradução. Conforme visto no excerto 1 , o IEEE deixa claro que o pagamento do serviço de tradução é de responsabilidade do autor e não garante a aceitação do trabalho para publicação (the use of an editing service is paid for by the author and does not guarantee acceptance in an IEEE publication ${ }^{11}$ ).

Em relação à falta de precisão, Lillis e Curry (2010) nos mostram que os tradutores encontram muita dificuldade na tradução do conteúdo nos níveis discursivos, uma vez que não pertencem à comunidade científica do autor. Isso reforça, novamente, a ideia de que apenas o domínio do código e das habilidades técnicas na língua inglesa não garante uma "comunicação mais eficaz", tal como postulado pelo excerto 1 , uma vez que as práticas de letramentos acadêmicos envolvem questões de natureza diferente.

Por outro lado, a pesquisa revelou que os pesquisadores preferem pedir auxílio na

\footnotetext{
${ }^{11} \mathrm{O}$ uso de um serviço de edição é pago pelo autor e não garante a aceitação em uma publicação do IEEE (tradução nossa).
} 
revisão de seus artigos em inglês aos mediadores acadêmicos, ou seja, colegas que fazem parte da mesma comunidade científica. Nestes casos, os mediadores reveem os textos de acordo com o discurso científico da área. Os autores, portanto, mostram-se mais satisfeitos com os mediadores acadêmicos (LILLIS; CURRY, 2010). Essa prática é explicitada no excerto 2, em que se sugere que a revisão seja feita por um colega nativo (Get a native English-speaking colleague to carefully proofread your paper ${ }^{12}$ ), estando indiretamente relacionada com a seção $\mathrm{V}$ do template em que são assinalados "alguns erros comuns", desde questões ortográficas, lexicais, semânticas a morfossintáticas.

É interessante notar como o IEEE, enquanto instituição, fornece orientações distintas aos autores filiados não falantes nativos de inglês: no Author Center, recomenda-se pagar por um serviço de tradução (excerto 1), enquanto que no template a indicação é pedir o auxílio de um colega nativo para a revisão do texto (excerto 2 ).

As recomendações presentes nos dois excertos podem, em um primeiro momento, ser compreendidas como ações para auxiliar o pesquisador que não se insere em um contexto anglófono. Entretanto, além de focalizarem apenas no domínio das habilidades técnicas, essas orientações depositam no sujeito a responsabilidade de divulgar sua pesquisa em uma língua que não a materna, mesmo em condições desiguais. Enquanto as ações forem pensadas no âmbito individual, as relações de poder entre o centro anglo-americano e a periferia, no que concerne à produção de conhecimento científico, não serão explicitadas e as práticas de letramentos acadêmicos centradas no inglês permanecerão perpetuando desigualdades.

\section{A cultura da velocidade}

É consenso que, no contexto científico-acadêmico em que vivemos atualmente, temse a demanda de maior produtividade e eficiência na produção e divulgação do conhecimento científico. Assim, importa sempre mais um item no currículo Lattes e, especificamente no Brasil, a produção (e, portanto, a publicação de artigos) de pesquisadores docentes em universidades públicas é um dos critérios para a promoção da carreira e para o financiamento de pesquisas pelas agências de fomento como Capes, CNPq e Fapesp, por exemplo. Nesse sentido, estabeleceu-se uma cultura da velocidade (BERG; SEEBER, 2016), na qual os pesquisadores, sobrecarregados com as inúmeras atividades que realizam como docentes $\mathrm{e}$ como pesquisadores, correm contra o tempo para publicar mais e de maneira mais rápida.

O IEEE, sendo um instituto criado pela e para a comunidade de pesquisadores da área das engenharias elétrica e eletrônica, também produz discursos que reagem às demandas desse contexto. No excerto 3, agrupamos frases de diferentes seções do website que ecoam o discurso da produtividade e eficiência na pesquisa acadêmica, o que se relaciona também à

\footnotetext{
${ }^{12}$ Peça a um colega falante nativo do Inglês para rever seu artigo cuidadosamente (tradução nossa).
} 
questão da cultura da velocidade e às práticas de letramentos acadêmicos. Vejamos a seguir:

\section{Excerto 3}

[a] Where you publish matters.

[b] Speed of publication.

Work smarter. Publish faster with IEEE.

[c] IEEE meets all your publishing needs.

[d] Preparing your article for submission is easy with IEEE author tools.

[e] First-time author? We can help.
Excerto 3 (tradução nossa)

[a] Onde você publica importa.

[b] Velocidade de publicação.

Trabalhe de maneira mais inteligente. Publique mais rapidamente com o IEEE.

[c] O IEEE atende a todas as suas necessidades de publicação.

[d] Preparar seu artigo para submissão é fácil com as ferramentas do autor do IEEE.

[e] Autor pela primeira vez? Nós podemos ajudar.

No livro "Slow Professor: challenging the culture of speed in the academy" (2016), Berg e Seeber criticam os valores associados à cultura da velocidade, predominante no ambiente científico-acadêmico: eficiência e produtividade. Para as autoras, nas últimas décadas, houve um aumento da pressão para trabalhar da forma mais eficiente possível, o que significa realizar as tarefas rapidamente e de modo mais produtivo. Ambos os valores resultam da corporatização das universidades (BERG; SEEBER, 2016) e estão associados à realização de atividades de forma mais acelerada para concretizá-las em um menor tempo. De acordo com as autoras, embora racionalmente se saiba que, para que haja alta qualidade nos trabalhos científicos, é necessário haver tempo para a pesquisa, o contexto da cultura da velocidade acaba privilegiando a quantidade de produção em detrimento da qualidade em todas as áreas do conhecimento.

É evidente que a noção da cultura da velocidade perpassa os enunciados presentes no excerto 3. A ideia de publicar mais rapidamente (Speed of publication. Publish faster with IEEE ${ }^{13}$ ) e mais facilmente (Preparing your article for submission is easy with IEEE author tools ${ }^{14}$ ) dialoga com os discursos institucionais que demandam uma alta produtividade. O IEEE, portanto, oferece serviços, tal como uma empresa, que supostamente podem aumentar a "eficiência" das práticas de escrita que envolvem o processo de publicação. No entanto, tal como discutido anteriormente, ao desconsiderar as relações de poder da esfera ideológica acadêmica (MIRANDA, 2017), o IEEE vincula ao desempenho apenas individual as questões de produtividade e eficiência, deixando de destacar os privilégios existentes (como, por exemplo,

\footnotetext{
${ }^{13}$ Velocidade de publicação. Publique mais rapidamente com o IEEE (tradução e sublinhado nossos).

14 Preparar seu artigo para submissão é fácil com as ferramentas do autor do IEEE (tradução e sublinhado nossos).
} 
pesquisadores que possuem o inglês como língua materna) nas práticas de letramentos acadêmicos, especialmente aquelas que envolvem contextos internacionais.

Com efeito, podemos trazer para a nossa análise o conceito de cenografia, que Maingueneau (2018) nos oferece. A forma como o IEEE enuncia a ideia de velocidade está obviamente apoiada numa certa representação daquilo que é ciência e de como ela deve ser difundida. A necessidade de publicar rapidamente está naturalmente associada à velocidade com que a tecnologia avança. Portanto, parafraseando as palavras do autor, não são apenas ideias que perpassam o discurso enunciado, mas sim uma representação que ali está incorporada. Ao percebermos toda uma rede de significados centrada na ideia de rapidez e facilidade, que o Author Center apresenta, acedemos a um mundo construído e assente nessa imagem. Para se entrar nele, não basta publicar, é preciso ser-se rápido. A ciência alimenta a indústria, e vice-versa, tornando a velocidade um valor maior. Assim, o IEEE constitui a cenografia na qual "tudo" acontece, associando uma "cronografia (um momento) e uma topografia (um lugar)" (MAINGUENEAU, 2018, p. 77), a partir de onde o discurso surge. Esse momento é o da cultura da velocidade e o lugar é a importância da instituição a nível mundial.

O ethos discursivo dá corpo a um enunciador, faz o leitor assimilar esse discurso e entrar nessa comunidade, porque existe uma cena "validada", ou seja, "já instalada na memória coletiva" e "valorizada" (MAINGUENEAU, 2018, p. 81). Dito de outro modo, seguindo determinadas etapas na produção de um artigo científico, assentes em representações de ciência validadas política, institucional e ideologicamente, cria-se um autor, alcança-se um modo de ser autor, assumindo tal caráter, já validado. A linguagem, ao se aproximar da esfera publicitária, cria um ethos, o enunciado se autolegitima, porque ao tentar convencer o leitor, se serve do seu imaginário ao "atribuir-lhe uma identidade invocando uma cena de fala valorizada" (MAINGUENEAU, 2018, p. 76).

É assim que "a cena validada é ao mesmo tempo exterior e interior ao discurso que a evoca" (MAINGUENEAU, 2018, p. 82), tendo em conta que o ethos dito e o ethos mostrado são congruentes com um sistema de valores e uma ideologia de uma cultura que hipervaloriza quantidade, eficiência, rapidez, audiência. Se por um lado é exterior porque "preexiste", ao mesmo tempo, é "produto do discurso, que a configura segundo seu universo próprio" (MAINGUENEAU, 2018, p. 82), ou seja, contribui para fomentar essa cultura da velocidade.

O Author Center desenha um ethos com certa autoridade científica e institucional para explorar discursos e construir mundos possíveis, em virtude da sua posição de autoridade, na medida em que as cenas que apresenta "fixam-se facilmente em representações estereotipadas" (MAINGUENEAU, 2018, p. 81).

Ao oferecer possibilidades de serviços para que os autores aumentem sua eficiência e produtividade, o IEEE está em consonância com a cultura da velocidade. Berg e Seeber (2016), ao contrário, defendem que é preciso resistir à corporatização das universidades que alimenta esse cenário. As autoras propõem o movimento Slow Professor. Partindo dos mesmos princípios do Slow Food, o movimento defende uma contracultura que perturbe o ethos 
corporativo de velocidade e que seja cética em relação à alta produtividade. Tal proposta nos parece muito pertinente, na medida em que o modo de fazer ciência em algumas áreas disciplinares acaba impondo, mais ou menos explicitamente, modos de produzir e divulgar o conhecimento em áreas cuja racionalidade epistêmica e ontológica é diferente, como é o caso, entre outros, das ciências sociais e humanas.

Ainda em relação ao excerto 3, julgamos importante ressaltar o oferecimento, pelo IEEE, de serviços pagos. As frases presentes nesse excerto foram publicadas em diferentes seções do website, mas, em relação à estrutura composicional, todas têm em comum o fato de serem a primeira frase escrita logo abaixo do título, destacadas em uma fonte maior.

Tais enunciados funcionam como slogans, uma vez que se constituem como frases de efeito (Where you publish matters ${ }^{15}$ ) e que utilizam estruturas léxicas (all your publishing needs; preparing your article for submission is easy; We can help ${ }^{16}$ ) e sintáticas (Work $\underline{\text { smarter/publish faster }}{ }^{17}$, com a rima entre "smarter" e "faster") típicas da esfera publicitária. Além disso, os enunciados também se relacionam às necessidades do público consumidor no contexto da cultura da velocidade, auxiliando ainda autores novatos no processo de escrita. Os enunciados talvez busquem, igualmente, seduzir e motivar os pesquisadores a adquirirem os serviços oferecidos pela fundação, tal como os slogans o fazem.

Nessa perspectiva, a produção de conhecimento pode ser entendida como um produto que é divulgado por meio da escrita e da publicação de artigos. As práticas de escrita acadêmica, por sua vez, tornam-se o objeto central dos serviços oferecidos pelo Author Center do IEEE, quase transformando os pesquisadores em clientes do instituto.

\section{Considerações finais}

A lógica cartesiana, que fragmentou o conhecimento disciplinar no Ensino Superior, influenciou dimensões da política, da ideologia e da gestão. Dito de outro modo, a fragmentação disciplinar, esquecendo e esbatendo a gênese epistemológica do saber e do conhecimento, influenciou a política, a ideologia e a gestão neste contexto. Assim se entende que, principalmente na pesquisa (mas não só), certas áreas disciplinares imponham padrões de publicação, ainda que suas materializações devessem ser avaliadas na esfera local e particular, tal como o campo dos letramentos acadêmicos defende. Concordamos com Wachowicz, quando reforça "a não separação entre conteúdo e forma no ensino superior e também a incorporação das técnicas de ensino e das relações com os alunos como

\footnotetext{
${ }^{15}$ Onde você publica importa (tradução nossa).

${ }^{16}$ Todas as suas necessidades de publicação; preparar o seu artigo para submissão é fácil; nós podemos ajudar (tradução e sublinhados nossos).

17 Trabalhe de maneira mais inteligente. Publique mais rapidamente com o IEEE (tradução e sublinhados nossos).
} 
intimamente ligadas ao conteúdo e à motivação que o professor vivencia em sua área" (2017, p. 35). A escrita acadêmica, seja ao nível do seu ensino ou da pesquisa, não constitui exceção. Da mesma forma que é imperativo articular ensino, pesquisa e extensão, é necessário também desenvolver e especializar o campo da escrita acadêmica, em detrimento de soluções de lógica "empresarial".

Uma outra consideração final diz respeito, naturalmente, à cultura atual de (des)informação, de comunicação, de imediatez e aceleração, próprias de uma globalização imaginada, como nos traz Canclini (2007). Ainda assim, resistindo à vigência deste paradigma, vários são os movimentos que encontramos, ora mais tímidos, ora mais contundentes, de contraposição a esta cultura científica. A nosso ver, no contexto brasileiro, ela precisa urgentemente de ser repensada e revista. As soluções uniformes, padronizadas e estandardizadas não promovem uma cultura científica qualitativamente saudável, emancipadora e promotora do conhecimento e da ciência.

Por último, o campo da escrita acadêmico-científica não deixa de ser influenciado e perpetuador, dependendo dos contextos, desta cultura científica, em que predominam visões homogêneas da escrita. Tal como Grossmann afirma, "a unicidade proclamada da ciência não esconde, por muito tempo, a diversidade das práticas científicas e, menos ainda, as partições entre os diferentes domínios científicos que fundam também compartilhamentos de disciplinas institucionalizados" (2015, p. 101). Da mesma forma, a escrita acadêmico-científica, seja ao nível do seu ensino, pesquisa e/ou divulgação, se enriquece quando assenta em concepções socioculturais que nos permitem pensar localmente em práticas de escrita acadêmico-científica heterogêneas e situadas, próprias de sujeitos, contextos disciplinares e instituições específicas. Julgamos que este é um dos possíveis caminhos a percorrer, com vista a uma avaliação mais qualitativa da produção e da divulgação da ciência na sociedade atual.

\section{Referências}

BERG, M.; SEEBER, B. K. The Slow Professor: challenging the culture of speed in the academy. Toronto: University of Toronto Press, 2016. https://doi.org/10.3138/9781442663091

CANCLINI, N. G. A globalização imaginada. São Paulo: lluminuras, 2007.

FIAD, R. S. A escrita na universidade. Revista da ABRALIN, v. Eletrônico, n. Especial, p. 357-369, 2011. https://doi.org/10.5380/rabl.v10i4.32436

FIAD, R. S. Reescrita, dialogismo e etnografia. Linguagem em (Dis)curso, Tubarão, v. 13, n. 3, p. 463-480, 2013. https://doi.org/10.1590/S1518-76322013000300002

FIAD, R. S. Algumas considerações sobre os letramentos acadêmicos no contexto brasileiro. Pensares em Revista, São Gonçalo, n. 6, p. 23-34, 2015. https://doi.org/10.12957/pr.2015.18424

FISCHER, A. Sentidos situados em eventos de letramento na esfera acadêmica. Educação, Santa Maria, v. 35, n. 2, p. 215-228, 2010. 
FISCHER, A.; COLAÇO, S. F. Práticas de escrita em ciências biológicas: letramentos acadêmicos (re)contextualizados. Raído, Dourados, v. 12, n. 27, p. 438-462, 2017. https://doi.org/10.30612/raido.v11i27.6751

FUZA, A. F. Diálogos entre discursos oficiais e dos periódicos acadêmico-científicos: as práticas sociais de escrita, de produção e de circulação do conhecimento. Raído, Dourados, v. 12, n. 27, p. 42-63, 2017. https://doi.org/10.30612/raido.v11i27.6746

GERALDI, J. W. Concepções de linguagem e ensino de português. In: GERALDI, J. W. (Org.). $O$ texto na sala de aula; leitura e produção. Cascavel: Assoeste, 1984, p. 41-49.

GROSSMANN, F. Por que e como as coisas mudam? Padronização e variação no campo do discurso científico. In: RINCK, F.; BOCH, F.; ASSIS, J. A. (Orgs.). Letramento e formação universitária: formar para a escrita e pela escrita. Campinas: Mercado de Letras, 2015, p. 97128.

IEEE. IEEE Author Center. Disponível em: https://ieeeauthorcenter.ieee.org/. Acesso em 17 mar. 2019.

KOCH, I. V. A inter-ação pela linguagem. 5. Ed. São Paulo: Contexto, 2000.

LANKSHEAR, C.; LEANDER, K. M. Social science research in virtual realities. In: SOMEKH, B.; LEWIN, C. (Orgs.). Research methods in the social sciences. London: Sage Publications, 2005, p. 326-334.

LEA, M.; STREET, B. Student writing in higher education: an academic literacies approach. Studies in Higher Education, v. 23, n. 2, p. 157-173, 1998. https://doi.org/10.1080/03075079812331380364

LEA, M.; STREET, B. The "Academic Literacies" Model: Theory and Applications. Theory into practice, v. 45, n. 4, p. 368-377, 2006. https://doi.org/10.1207/s15430421tip4504 11

LILLIS, T.; CURRY, M. J. Academic writing in a global context: the politics and practices of publishing in English. New York: Routledge, 2010.

LÜDKE, M.; ANDRÉ, M. E. D. A. Pesquisa em educação: abordagens qualitativas. São Paulo: EPU, 1986.

MAINGUENEAU, D. Ethos, cenografia, incorporação. In: AMOSSY, R. (Org.) Imagens de si no discurso: a construção do ethos. São Paulo: Contexto, 2018, p. 67-92.

MARCUSCHI, L. A. Produção textual, análise de gêneros e compreensão. São Paulo: Parábola Editorial, 2008.

MIRANDA, F. D. S. S. Dimensões cruzadas: escritas de universitários como apresentações discursivas na esfera ideológica acadêmica. Raído, Dourados, v. 12, n. 27, p. 83-104, 2017. https://doi.org/10.30612/raido.v11i27.5734

PASQUOTTE-VIEIRA, E. A. Letramentos Acadêmicos: a aliança entre linguística e etnografia. Estudos Linguísticos, São Paulo, v. 44, n. 2, p. 695-710, 2015.

SÁ-SILVA, J. R.; ALMEIDA, C. D.; GUINDANI, J. F. Pesquisa documental: pistas teóricas e metodológicas. Revista Brasileira de História e Ciências Sociais, São Leopoldo, v. 1, n. 1, p. 01 15, 2009.

STREET, B. Literacy in theory and practice. Cambridge: CUP, 1984. 
STREET, B. What's "new" in New Literacy Sudies? Critical approaches to literacy in theory and practice. Current Issues in Comparative Education, v. 5, n. 2, p. 77-91, 2003.

STREET, B. "Hidden" Features of Academic Paper Writing. Working Papers in Educational Linguistics, v. 24, n. 1, p. 01-17, 2009.

WACHOWICZ, L. A. O Ensino superior e suas relações com a cultura. In: BARBOZA, M. A.; TEIXEIRA, I. A.; Costa, M. P. L. (Orgs.). Territórios da Docência no Ensino Superior. Curitiba: CRV, 2017, p. 27-40.

Recebido em: 18/03/2019

Aceito em: 30/04/2019 